\title{
Coordination in the Science System: Theoretical Framework and a Case Study of an Intermediary Organization
}

\author{
Laurens K. Hessels
}

Published online: 4 June 2013

(C) Springer Science+Business Media Dordrecht 2013

\begin{abstract}
Many science systems are witnessing the rise of intermediary organizations with a coordinating mission, but to date a systematic understanding of their function and effects is lacking. The aim of this paper is to contribute to the understanding of the coordinating efforts of intermediary organizations. Starting from the definition of coordination as the establishment or strengthening of a relationship among the activities in a system, with the aim to enhance their common effectiveness, I develop a heuristic framework that facilitates the systematic analysis of coordination in science. I illustrate and substantiate my framework with the empirical case study of a Dutch coordination task force in the area of chemical technologies. Thanks to the framework I could disentangle a number of functions that this task force fulfils concerning research programming, funding allocation and supporting interactions and collaborations. This approach enabled me to systematically analyse a very heterogeneous set of processes that each deserve to be called coordination. The analysis yields a clear overview of eight coordination processes that are each described in terms of activities, intervention, relationships, mechanisms and performance. I conclude my paper with suggestions for further research on coordination in the science system.
\end{abstract}

Keywords Coordination - Science policy · Intermediary organization · Innovation $\cdot$ Research programme

\section{Introduction}

As they are generally seen as a key to improving the innovative capacity, publicprivate partnerships receive generous support of science and innovation policies

L. K. Hessels ( $\square)$

Rathenau Instituut, PO Box 95366, 2509 CJ Den Haag, The Netherlands

e-mail: 1.hessels@rathenau.nl 
(Potì and Reale 2007; Fisher et al. 2001; Gray 2011). Public-private partnerships (PPPs) tend to take the form of collaborative networks or research consortia that can be classified as intermediary organizations. Mediating between the government and the research performance level, they offer a solution for delegation problems in science policy (Braun 2003). In the Netherlands, for example, several coordinating bodies have been established to boost scientific progress and innovation in strategic areas (van der Meulen and Rip 1998; Versleijen 2007). They bring together researchers with different disciplinary and institutional backgrounds in order to enhance scientific productivity, economic competitiveness and/or social development.

With the rise of PPPs, a new type of organization has entered the science system with a hybrid mission that can be summarized as coordination. Such intermediaries typically fulfil various interrelated functions, ranging from the allocation of funding (Klerkx and Leeuwis 2008) to negotiations about subsidies and legitimacy (Kearnes and Wienroth 2011).

From a policy perspective, a systematic understanding of this new organization is desirable to enable performance evaluation and evidence-based decision making. Although coordination is usually considered desirable, it comes with a price. Even if coordinating bodies do not require large financial investments, they might absorb substantial amounts of time that academics would have otherwise spent on research. Moreover, if there are too many coordinating bodies, they may interfere with or inhibit each other's effects. To date, however, the understanding of coordinating intermediaries is limited.

The aim of this paper is to contribute to the understanding of the coordinating efforts of intermediary organizations in the science system. To this end, I will provide a theoretical elaboration on the notion of coordination based on a combination of science policy literature and socio-economic theories of coordination. I will illustrate and substantiate my theoretical framework with an empirical case study of ACTS, a Dutch task force with the mission to stimulate and coordinate research in the area of chemical technologies.

\section{Theoretical Framework}

As a first step towards the development of a theoretical framework on coordination in science, let us briefly review existing literature on this topic. The notion of coordination has been applied many times in science (policy) studies to describe and analyse a variety of different phenomena, ranging from collaborations between individual researchers within a common research project to the mutual adjustment between national policies for science, innovation and education. Within this diversity, three categories of topics can be identified: the academic system, science and innovation policies, and collaborations, respectively (see Table 1). Although these various papers have different goals than mine, they do offer useful building blocks for a coherent definition of coordination in science.

First, some studies focus on coordination in the academic system as a whole, that is, on the interactions among the researchers, organizations and institutions that shape the progress of science. Whitley (2003) speaks of 'intellectual coordination' 
Table 1 Contributions to science (policy) studies dealing prominently and explicitly with coordination

\begin{tabular}{|c|c|c|c|}
\hline $\begin{array}{l}\text { Domain of } \\
\text { application }\end{array}$ & Authors & Explicit definition & Implicit definition \\
\hline \multirow{4}{*}{$\begin{array}{l}\text { Academic } \\
\text { system }\end{array}$} & Whitley (2003) & & Task division across research sites \\
\hline & $\begin{array}{l}\text { Van Lente \& Rip } \\
\quad \text { (1998) }\end{array}$ & & $\begin{array}{l}\text { Mutual positioning and agenda } \\
\text { building by technological } \\
\text { expectations }\end{array}$ \\
\hline & Clark (1979) & & $\begin{array}{l}\text { Processes creating order in loosely } \\
\text { coupled systems }\end{array}$ \\
\hline & Polanyi (1962) & & $\begin{array}{l}\text { Independent initiatives adjusting } \\
\text { themselves consecutively to the } \\
\text { results achieved by others }\end{array}$ \\
\hline \multirow[t]{5}{*}{ Policy } & Lepori (2011) & $\begin{array}{l}\text { 'organizing social action } \\
\text { in a world where there } \\
\text { is no overall mind' } \\
\text { (p. 359) }\end{array}$ & \\
\hline & Clark (2010) & & $\begin{array}{l}\text { Managing linkages among } \\
\text { innovation policy (at different } \\
\text { scales) and regional development } \\
\text { policy }\end{array}$ \\
\hline & Braun (2008) & & $\begin{array}{l}\text { Creating efficiency and coherence } \\
\text { among various public policies }\end{array}$ \\
\hline & $\begin{array}{l}\text { Edler \& Kuhlmann } \\
\quad \text { (2008) }\end{array}$ & & $\begin{array}{l}\text { Task division and mutual } \\
\text { adjustment among policies across } \\
\text { organizations and across levels of } \\
\text { aggregation }\end{array}$ \\
\hline & Van Vught (1997) & & $\begin{array}{l}\text { Mechanisms underlying } \\
\text { governmental policy strategies }\end{array}$ \\
\hline \multirow[t]{3}{*}{ Collaborations } & Sundberg (2011) & & $\begin{array}{l}\text { Task division among researchers in } \\
\text { a collaborative project }\end{array}$ \\
\hline & $\begin{array}{l}\text { Cummings \& Kiesler } \\
\text { (2007) }\end{array}$ & $\begin{array}{l}\text { 'activities that help } \\
\text { project teams integrate } \\
\text { and best utilize their } \\
\text { expertise' (p. 1622) }\end{array}$ & \\
\hline & $\begin{array}{l}\text { Bonaccorsi and } \\
\text { Piccaluga (1994) }\end{array}$ & $\begin{array}{l}\text { 'behavioural rules } \\
\text { emerging from } \\
\text { ongoing interaction } \\
\text { between the parties' } \\
\text { (p. 238) }\end{array}$ & \\
\hline
\end{tabular}

Note that other publications discuss similar phenomena using notions like governance, adjustment or alignment (Bonaccorsi 2008). Although I have not included these in the overview, some of them have informed my framework presented in the latter part of this section

as a social process among scientists in which tasks are divided and individual contributions are made compatible through common research procedures and routines. Van Lente and Rip (1998) focus on coordination by technological expectations. They claim that a shared future vision of a promising technology can steer the actions of scientists, policymakers, firms and others. Burton Clark (1979) regards coordination pathways as 'basic processes that link fields of study and institutions together so as to compose systems' (p. 255). Polanyi (1962) discusses 
'self-coordination', which means that researchers adjust their activities spontaneously to the results achieved by others, guided by a quasi-economic 'invisible hand'.

A second-and relatively large-category contains studies dealing with the coordination of science and innovation policies. Within this category, some studies deal with one policy domain in particular so that their analyses concern mainly the relationship between the government (as a principal) and the research performing organizations (as agents). Lepori (2011) focuses on science policy and provides a framework for analysing public funding systems in terms of 'coordination modes', 'prototypical ways of organizing social action in a world where there is no overall mind' (p. 359). The analysis of van Vught (1997) deals with higher education policy and distinguishes 'planning' and 'market' as two coordination mechanisms in this domain.

Other contributions specifically address the interactions among different policies. In 2008, a complete special issue of Science and Public Policy (issue 35, number 4) has been dedicated to the coordination of knowledge and innovation policies. Braun uses a functional definition of coordination, referring to efficiency and coherence as its main objectives. Based on existing literature, he distinguishes between functional and administrative coordination, which can each be further specified as strategic coordination versus policy integration and positive versus negative coordination, respectively (Braun 2008). Edler and Kuhlmann (2008) analyse formal and informal interactions and relationships among ministries and governmental agencies, and assess to what extent these contribute to the common effectiveness of their policies. The study by Jennifer Clark (2010) deals with innovation and development centres in the US and Canada and distinguishes between vertical coordination (linkages among STI policy on various scales) and horizontal coordination (collaboration and communication among different centres).

Third, some scholars have analysed specific processes on the micro-level, such as collaborations between individual researchers or collaborations between universities and firms. Cummings and Kiesler apply coordination to collaborative research projects. For them, coordination activities are 'activities that help project teams integrate and best utilize their expertise' (Cummings and Kiesler 2007: 1622). Similarly, Sundberg's study (2011) focuses on a specific kind of collaboration. In her paper, coordination refers to the task division among individual researchers within a certain specialty in loosely organized collaborations. Sundberg shows how 'intercomparison projects' in astrophysics, oceanography and meteorology determine which researchers are working on a particular problem. Bonaccorsi and Piccaluga (1994) use the notion of 'coordination procedures' in their analysis and taxonomy of university-industry relationships. These refer to "soft" managerial aspects in interorganisational relationships that might determine their outcome irrespective of the "hard" structure features'.

\section{A Working Definition of Coordination in Science}

The literature review above indicates that consensus about a coherent and convincing concept of coordination in science is lacking. As scholars have used 
the notion of coordination to study various phenomena, with different goals, it is not surprising that their (implicit or explicit) definitions of coordination vary (see Table 1). Some studies use the term coordination to denote soft governance and spontaneous interactions, in contrast with hierarchical rules or management (e.g. Polanyi, Bonaccorsi and Piccaluga). In other contributions (e.g. Lepori, van Vught) the term has a broader meaning comprising both hierarchical power and other governance aspects.

In order to understand the mission of intermediary organizations, the existing notions of coordination in science do not suffice; they are either too narrow or too broad. Most of the definitions found in science (policy) studies are too restrictive to describe the variety of functions of intermediary organizations in science. For example, the definition of coordination by Cummings and Kiesler (2007) as 'activities that help project teams integrate and best utilize their expertise' (p. 1622), is obviously limited to collaboration within given project teams. Interactions across projects, or processes of mutual adjustment at the policy level are not included in this definition. And Whitley's concept of coordination (2003) refers to task division across research sites, while (1) coordination can also occur at one particular location, and (2) a competition among researchers each working on the same topic should also count as coordination.

In contrast with these restrictive notions of coordination, the concepts used by Lepori (2011) and Clark (1979) are too broad to serve my current purpose. Lepori's definition of coordination as 'organizing social action in a world where there is no overall mind' (p. 359) and Clark's (implicit) idea of coordination as 'creating order in loosely coupled systems' are both inspiring, but further specification is required. How can social action be organized, or how can order be created?

In order to develop a more specific formulation, I build on the interdisciplinary study by Malone and Crowston who define coordination as 'managing dependencies between activities' (Malone and Crowston 1994: 90). However, a couple of changes are necessary. First, the idea of 'dependencies' deserves to be extended to relationships in general. Some relationships addressed in earlier literature about coordination in science, such as competition (Polanyi 1962; Lepori 2011), are not easily conceived as dependencies: two competing activities are dependent on a common resource rather than on each other. For this reason, I broaden the idea of dependencies and include any relationships that can contribute to the effectiveness of all activities present in the science system. What kinds of relationships these are is an empirical question, but to illustrate the variety of possibilities I will list some examples of relationships that may contribute to the performance of a system:

- Similarity: if two activities share a number of characteristics, this can lead to synergies between them. For example, a coherent research programme might be more effective than a random combination of independent projects.

- Complementarity: to avoid wasting resources, task division can be fruitful: adjusting the scope or focus of different activities can help to avoid duplication.

- Competition: making several activities dependent on a common finite set of resources can be a strong incentive to increase the effectiveness of each activity. 
- Acquaintance: mutual awareness among activities can help to exploit possible synergies.

- Collaboration: sharing resources such as data, funding or knowledge can increase the efficiency of activities.

- Synchronicity: purposeful timing of activities can increase their common effectiveness, for example when one activity can give input to another, or when both depend on a certain facility that can only serve one at the time.

- Proximity: geographical distance reduces the probability of physical contact, mutual learning and exploiting spillovers, so locating several activities close to each other can increase their effectiveness.

The second necessary adaption is the explicit inclusion of an effect. In everyday discourse it is only appropriate to speak of coordination when the effectiveness of a system is improved. If a director attempts to make the musicians in an orchestra play in tune to improve its performance but fails to do so, one would not speak about coordination. Analytically, however, the requirement of enhanced effectiveness is difficult to hold. First, it is methodologically very difficult to measure effects on a system-level as they often emerge on a longer term. Second, these effects can impossibly be determined objectively, as any concept of system performance by definition has a normative dimension, because it depends on the subject's values and his perspective on the given system. For this reason we define coordination not as the realization of enhanced effectiveness, but rather as aiming for enhanced effectiveness. In this context, 'effectiveness' can concern any conceivable type of output or performance of the system, such as productivity, innovation or prestige. In fact, a coordinating actor can give any meaning to effectiveness as long it concerns a desired effect on the level of the system rather than on the level of individual activities.

Incorporating these two aspects into the definition by Malone and Crowston results in the following definition of coordination: the establishment or strengthening of a relationship among the activities in a system, with the aim to enhance their common effectiveness.

In the context of the science system, this notion of coordination can be applied to activities of various natures, on multiple aggregation levels, serving various goals. I will give three examples to illustrate the applicability of this definition:

- A competitive funding instrument coordinates if it strengthens the competition among different researchers in order to enhance their common productivity.

- A regular meeting between the directors of two research councils can be a form of coordination when it helps to establish synchronicity among different policy instruments, aiming to enhance their common effectiveness.

- The agreement between two universities to settle on a task division regarding their research agendas could be defined as the establishment or strengthening of complementarity among the research activities of different organizations, by which the organizations hope to enhance their common societal impact.

It is crucial to distinguish between spontaneous and intentional coordination. Intentional coordination implies that a particular actor chooses to intervene in a 
system aiming to enhance its performance (whatever this means to the actor). Spontaneous coordination lacks such a goal at the system level. It simply emerges from the behaviour of individual actors that are each acting for their own benefit without caring about a goal on the system level. The research system contains a complex combination of both forms of coordination.

Researchers interact with each other on multiple levels of aggregation. On the operational level, individual researchers have regular contact with colleagues within their own group or organization, and with fellow researchers in their scientific field. On top of that, group leaders and other managers also interact with each other to discuss university politics, policy and management issues. And on the level of scientific fields, prominent scientists act as spokespersons that present the progress and promises of their field to other fields and to a broader environment. We can assume that in these interactions each of the actors acts (primarily) for their own benefit, but still, coordination can emerge spontaneously as a result of their individual actions (Polanyi 1962). For example, researchers compete for priority of inventions and discoveries (Dasgupta and David 1994) and for scarce resources (Ziman 1994). Their competitive relationship might lead to higher performance on the system level. Moreover, researchers or research organizations may also decide to collaborate by exchanging knowledge or other resources for their own benefit (Bozeman and Corley 2004), thereby creating (spontaneous) benefits on the system level as a side effect.

Intentional coordination is an intervention in a system, motivated by the perception that existing (spontaneous) forms of coordination will fail. The actors can choose from two possible strategies to intervene. First, they can strengthen an existing coordination process. For example, by offering an open call for research proposals a research council might strengthen the existing competition among researchers. Second, they can decide to introduce a new coordination process, such as a market place where supply and demand of a specific kind of knowledge meet each other, or a rule that forces researchers to publish their findings in open-access journals. Note that the distinction between spontaneous and intentional coordination is sometimes blurred. For example, somebody organizing a conference may do so for the benefit of his or her field, but also to gain a personal reputation. Given my interest in intermediary organizations that have the explicit task to intervene in the science system, the remainder of this paper will primarily deal with intentional coordination.

\section{A Heuristic Tool for Analysing Coordination in Science}

In order to systematically characterize coordination processes in the science system, here I will introduce a heuristic based on seven key aspects:

1. The coordinating actor: many different individuals or organizations can conduct coordination, such as a group leader, a research council or the Minister of Science Policy.

2. The system addressed: coordination can address systems of various levels of aggregation, such as a research group, a scientific field or a set of funding instruments. 
3. The activities in this system that are subject to coordination: coordination may address research activities, but it may also address other activities that are part of science, such as funding allocation, foresight or research management.

4. The intervention taken to modify the relationships among these activities: this aspect concerns the action taken to influence a system, such as changing the law, organizing regular meetings, launching a technological promise or installing a supervisory board.

5. The types of relationships that are established or strengthened by this intervention: as indicated above, a variety of relationships may be involved, such as collaboration, complementarity and synchronicity.

6. The mechanism making it possible that these relationships enhance the effectiveness of the system: how can the new or strengthened relationships enhance the system's performance? This crucial aspect is responsible for the possibility to coordinate. For example, collaborative relationships enhance the performance of a system thanks to mutual learning and efficient usage of resources.

7. The kind of performance of the system that the actor aims to enhance: the effectiveness of a system can be conceived along various dimensions, according to the perspective of the coordinating actor.

This heuristic does not adopt the typology of markets, hierarchies and networks, which is common in sociological economic literature on coordination (Powell 1990; Thompson et al. 1991). When analysing coordination processes in science, one will often come across characteristics associated with markets, hierarchies and networks. If one conceives funding decisions as transactions, funding mechanisms are manifestations of different 'coordination modes' (Lepori 2011). Competitive project funding by research councils can be modelled as a market, while block grant funding is allocated in a more hierarchical way. However, in reality, many funding mechanisms are ruled by mixes of coordination modes, rather than individual ones (Lepori 2011). Competitive relationships, hierarchical decisions and collaborations based on mutual trust are common features of the scientific enterprise, and it is tempting to link them with the market, a hierarchy and a network, respectively. However, when broadening the perspective beyond research funding, a classification of processes in terms of these general categories will not help to distinguish systematically between different coordination processes, as these characteristics refer to different aspects of the process. A hierarchical decision refers to the intervention that an actor makes to coordinate, competition concerns the relationships involved, while trust is a mechanism that makes it possible to turn relationships into higher effectiveness. Classifying coordination processes in terms of socio-economic ideal types can lead to caricatures. For a systematic characterization, a more fine-grained heuristic as presented above will be indispensable. Although I have explicated the various aspects with several examples, empirical analysis will have to reveal what kinds of actors, systems, activities, interventions, relationships, mechanisms and performance are involved in coordination in science. As a first step in this direction, in the remainder of this paper I will apply the heuristic to a case study of a Dutch intermediary organization with a coordinating mission. 


\section{Methods: Case Study}

As a first empirical test of the framework developed above, I will now present a case study of the Dutch task force Advanced Chemical Technologies for Sustainability (ACTS). A case study seems an appropriate method as it will yield in-depth and contextualized insights into the workings of intentional coordination processes. The exploratory observations in this case can obviously not be generalized without taking into account the specific national and disciplinary setting of this case. In a later stage the preliminary conclusions of this case study should be complemented using quantitative methods such as funding analysis, surveys or bibliometrics.

ACTS is an interesting case, as it has been established with an explicit coordinating mission: 'ACTS is a public private partnership between Dutch government, universities, research institutes and industry in the field of sustainable chemical technologies. Its mission is to initiate and support the development of innovative technologies for the sustainable production of materials and energy carriers. ACTS realises this mission by establishing and coordinating challenging public private research programmes in accordance with the business plan of the Regiegroep Chemie. These programmes consist of a coherent cluster of projects, executed by universities and research institutes in close cooperation with industrial partners' (www.nwo.nl/acts, 29 December 2011).

This mission statement indicates that ACTS intends to fulfil a boundary role between different institutional and epistemic cultures. Its aim is to establish intensive collaboration between research activities of public research organizations, on the one hand, and industry, on the other. Moreover, it strives for coherent clusters of projects, implying alignment of the work of researchers with different disciplinary backgrounds. The following section will show what interventions it makes to this end.

Interestingly, ACTS is a relatively autonomous organization, but it is organizationally associated with NWO (Nederlandse Organisatie voor Wetenschappelijk Onderzoek), the general Dutch research council. This special status implies a possibility to develop a tailor-made approach to coordination, but it also implies a need to maintain relationships with established parties.

ACTS was established in 2002 as part of a shift towards consortia-based funding in the Dutch science system (Hessels and van Lente 2011). My analysis focuses on its first cohort of research programmes (see Table 2). The new set of programmes that ACTS is currently implementing under the heading of Technology Areas for Sustainable Chemistry (TASC) falls beyond the scope of this paper.

The case study is based on document analysis and interviews. Strategy documents, annual reports, evaluations and programme websites have provided insights into the mission of ACTS and its programmes, visions on coordination, actual coordination processes and (where possible) the effects of coordination. In total, 27 interviews were conducted ${ }^{1}$ with researchers, programme committees, ACTS board members and other actors involved in ACTS programmes (see Table 3). For the interviews, we narrowed our focus to three programmes (B-Basic,

\footnotetext{
1 The interviews were conducted by the author or by research assistant Pepijn Wesselman.
} 
Table 2 General information about the first cohort of ACTS research programmes

Source: ACTS website (21

February 2011). Amounts are total budgets including industrial contributions and 'matching' budgets from universities

\begin{tabular}{lll}
\hline Programme & Duration & $\begin{array}{l}\text { Budget } \\
\text { (M€) }\end{array}$ \\
\hline $\begin{array}{l}\text { ASPECT (Advanced sustainable processes } \\
\text { by engaging catalytic technologies) }\end{array}$ & $2004-2012$ & 12.5 \\
$\begin{array}{l}\text { B-Basic (Bio-based sustainable industrial } \\
\text { chemistry) }\end{array}$ & $2004-2009$ & 50 \\
$\begin{array}{l}\text { IBOS (Integration of biosynthesis and } \\
\quad \text { organic synthesis) }\end{array}$ & $2003-2012$ & 13.6 \\
$\begin{array}{l}\text { PoaC (Process on a chip) } \\
\text { Sustainable hydrogen } \\
\text { Total }\end{array}$ & $2004-2013$ & 8 \\
\hline
\end{tabular}

Sustainable Hydrogen and PoaC) to enhance the coherence of our dataset and to facilitate triangulation. We asked researchers questions about their participation in ACTS, in particular concerning funding acquisition, research evaluation, interactions and collaborations. Interviews with others dealt with agenda-setting processes, project selection, programme management and perceived outcomes of ACTS.

The findings were analysed using the heuristic framework on coordination processes developed above. Combining the insights gained from interviews and documents, I have made an inventory of active coordination processes at ACTS. In the following section, I will present my observations about these processes in terms of the seven aspects listed above. In this endeavour I focus on modes of coordination that can be empirically observed rather than the coordination logics guiding the actors involved.

\section{Results}

At ACTS I observed eight different coordination processes. ACTS contains many different functions and processes, eight of which can be characterized as interventions that establish or strengthen relationships among the activities in a system, which enhance their common effectiveness. Two actors make these

Table 3 Interviews conducted for the case study of ACTS

\begin{tabular}{lc}
\hline Function/level & Number of interviews \\
\hline Executive board members & 4 \\
Programme committees & 7 \\
Programme officers & 2 \\
Sub-programme leader & 1 \\
Researchers & 10 \\
Industrial partners & 2 \\
Other stakeholders & 1 \\
Total & 27 \\
\hline
\end{tabular}


interventions: the executive board (EB) and the programme committees of the different programmes of ACTS. These actors coordinate systems of different aggregation levels. The coordination processes of the EB address chemical technologies in general, while the programme committees each coordinate activities in a specific field or sector. A further distinction can be made between processes that exclusively address activities within ACTS, and processes extending beyond its boundaries (see Table 4). The three processes identified 'within ACTS' are internal interventions, only concerning relationships among activities part of ACTS. The other five processes have a broader scope. These do not only address activities within ACTS, but also activities of other researchers, firms and funding organizations.

In the following, these processes will be characterized in more detail, describing the other five aspects of my heuristic framework: the activities, intervention, relationships and mechanism involved, and the kind of performance aimed for. Where possible, I will also indicate whether the aspired performance has been accomplished. I will first characterize four generic coordination processes (Table 5), and then characterize four coordination processes that I found in specific programmes or sectors (Table 6).

\section{Bundling Research Plans}

In the domain of chemical technologies, the acquisition power of a combined set of research proposals turns out considerably larger than the sum of its parts. By proposing a coherent research programme addressing a theme considered interesting for society and or the economy, researchers can together acquire a lump sum of public funding. The various ACTS programmes each have their own 'birth history', but in all cases this governmental support has made it attractive for industry to join as a co-sponsor. Given this public support, the programmes enable firms to explore new innovation directions for a relatively low price. Firms are interested in participating in these programmes for the knowledge these produce, for the sake of networking with scientists and other firms, and for educating and scouting new R\&D staff. The firms typically pay only about $25 \%$ of all costs and still have a significant influence on the programme goals and priorities. By aligning and combining their research proposals, the researchers join forces and negotiate collectively with firms, just like a labour union or farmers cooperation would. The total amount of money acquired for the various ACTS programmes (see Table 2)

Table 4 Overview of the coordination processes in terms of the system addressed

\begin{tabular}{lll}
\hline Coordinating actor & Coordination processes within ACTS & Coordination processes beyond ACTS \\
\hline Executive board & Bureaucratic efficiency & Bundling research plans \\
& & Alignment with NWO-CW \\
& & Alignment with other parties \\
Programme committees & Interactions within programmes & Platform for research programming \\
& Protecting IP & Competitive project selection \\
\hline
\end{tabular}




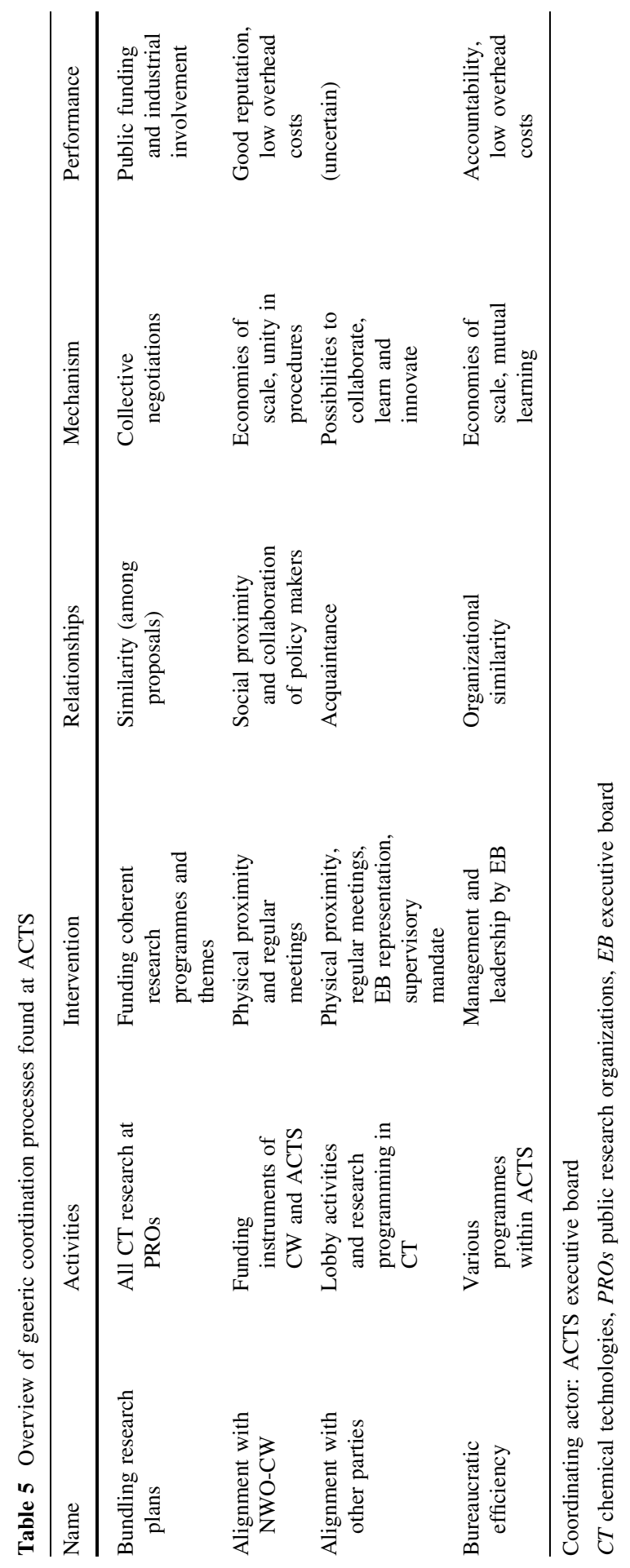




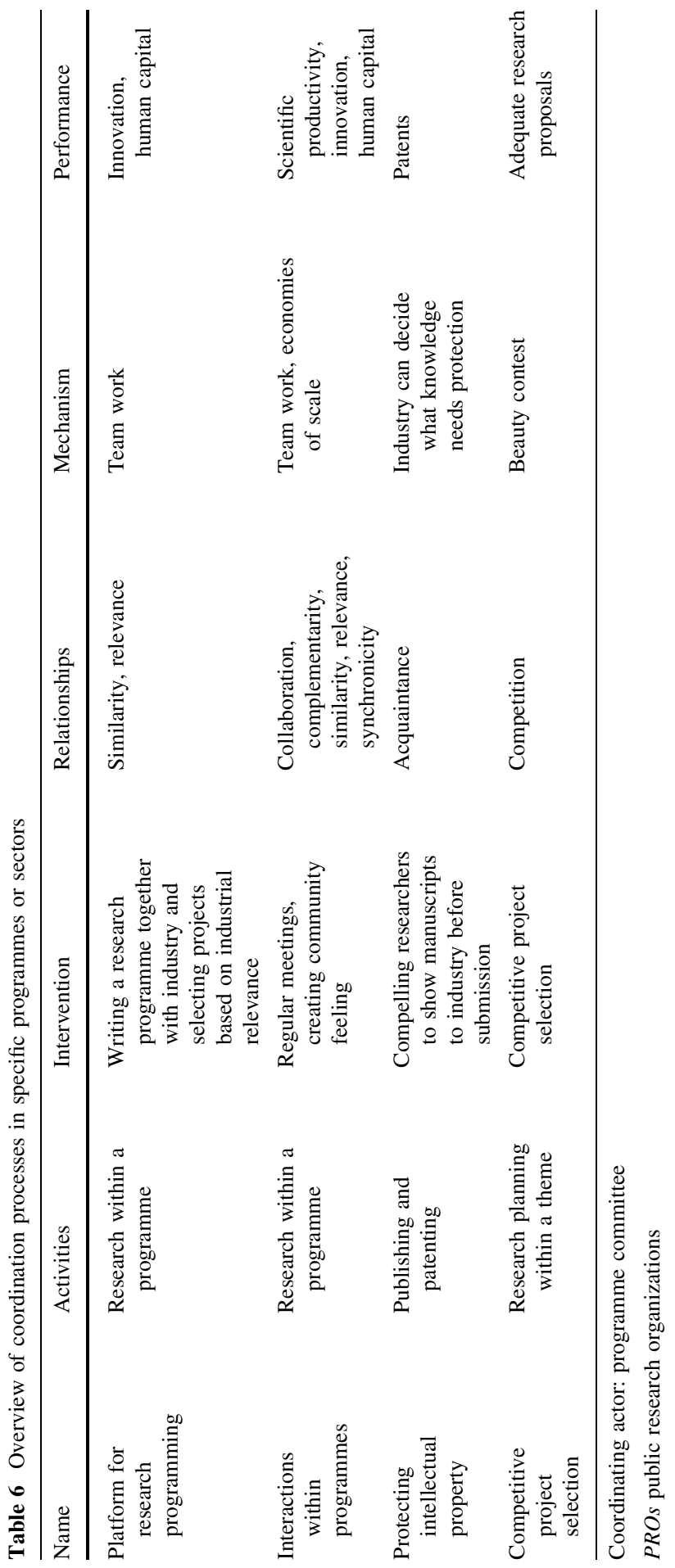


indicates that this is a strong coordination mechanism. Both researchers and industrial stakeholders have expressed that these investments would be much lower without these programmes.

\section{Alignment with NWO-CW}

The office and the board of ACTS both function in close cooperation with the division for chemical sciences (CW) of the Dutch research council NWO. Both organizations share an office and several staff members, including a common director. During regular staff meetings and by informal contact, both organizations inform each other about their activities. This close collaboration enables the staff to create several synergies. First and foremost, ACTS can build on NWO's long tradition and reputation of implementing research programmes. Thanks to their close proximity, staff members can share both codified knowledge and tacit knowledge about organizing competitive project selection and about keeping administration of running projects. This learning from its sister organization saves ACTS time, and it also strengthens its legitimacy. For all actors involved, the integration of ACTS within NWO indicates that fair procedures will be guaranteed, regardless of industry involvement. Strikingly, many of the researchers receiving ACTS funding do not conceive of ACTS as a separate entity and use the names ACTS and NWO interchangeably. A second synergy concerns the sharing of networks. For the planning and implementation of their activities, both organizations strongly depend on the Dutch chemical community: they need research leaders to initiate programmes and write programme outlines, referees to conduct peer reviews of project proposals, and industrial R\&D managers for participating in, supervising or supporting programmes. Third, the ACTS board indicates that a purposeful planning of its activities in relation to the activities of NWO-CW can increase their common effectiveness. For example, the experiences in a relatively fundamental research programme of NWO-CW could lead to an initiative to explore the possibilities of starting a more application-oriented programme in a related area in ACTS. Or, alternatively, a particular initiative in one of the two organizations could be put on hold if it seems that there will be too much overlap with an upcoming programme in the other domain. ${ }^{2}$

\section{Alignment with Other Parties}

ACTS has both formal and informal ties with several associated organizations in order to enhance their common performance. First, the Dutch research school for catalysis (NIOK) and its industrial advisory board (VIRAN) have located their secretariats within the ACTS office to facilitate mutual adjustment, and both have a seat in the ACTS Executive Board. Thanks to their close proximity they are well

\footnotetext{
${ }^{2}$ It must be noted that these synergies do not apply to all programmes to the same extent. B-Basic, the largest programme of ACTS, amounting to about half of its total budget, was initiated outside ACTS in the context of the governmental Bsik framework for improving the Dutch knowledge infrastructure. As a requirement for this funding instrument, all research funding was already assigned to individual projects before it became part of ACTS. Moreover, its project administration has been divided between the ACTS office and a dedicated office at the Technical University Delft.
} 
acquainted with each other's activities, which increases the possibilities to collaborate and benefit from each other's knowledge and networks. However, we have no indication that this significantly enhances their performance. Second, ACTS is formally connected with the Regiegroep Chemie (RC), a powerful lobby club of industrial and academic leaders. Given its power and prestige, ACTS has decided to install RC as its supervisory board. Our interviews indicate close, informal contacts among ACTS representatives and the RC members, but RC's official role as a supervisory board seems very limited. Altogether, thanks to regular interaction ACTS can keep a close watch on developments and activities of some associated organizations, but to what extent this increases its performance is unknown.

\section{Bureaucratic Efficiency}

The bundling of several programmes in ACTS has several advantages in terms of bureaucratic efficiency. The ACTS board demands the programmes to conform to a number of organizational standards, mainly concerning the procedures for funding allocation and agreements about intellectual property. The organizational similarity of the programmes enables ACTS to benefit from economies of scale. Experiences with patents in one programme can be used to improve the IP agreements in other programmes. Moreover, in order to facilitate fruitful university-industry collaborations, ACTS enables the programmes to learn from each other. This happens with respect to the complex, stepwise process of writing a research programme in collaboration and selecting projects based on both scientific excellence and industrial relevance. This helps to reduce overhead costs, but it also increases the accountability of the programmes. Their organizational similarities enhance their transparency for the research community, policymakers and industry. It must be noted that the programmes also differ in many respects, for example, regarding the precise role of industry in writing programme outlines and their influence in the selection of researchers. ${ }^{3}$

\section{Platform for Research Programming}

ACTS functions as a platform where academic researchers and industry meet around particular themes; it is a meeting place for knowledge supply and knowledge demand. Two main interventions make this coordination process possible:

1. the facilitation of formal or informal consultation of industry, and collective writing of research programme outlines

2. the inclusion of industrial relevance as a criterion in project selection

\footnotetext{
3 B-Basic has a deviating organizational structure. Its funding was already divided among projects in its design phase, so it did not organize an open competition. Moreover, it has a 'management team' next to its programme committee, and its administration is partly located at TU Delft rather than at the central ACTS office. One ACTS board member speaks of a "LAT relationship" (Living Apart Together) between ACTS and this programme. Our observations of this programme suggest that it does not benefit from the bureaucratic efficiency of the other four programmes.
} 
Programmes use various ways to organize discussions between university and industry. ASPECT and IBOS are based on a formal roadmap issued by the Ministry of Economic Affairs (Technology Roadmap Catalysis: Catalysis, key to sustainability 2002). The other programmes and their calls for proposals are based on more informal brainstorms and debating sessions:

'With the second call that we had, we clearly said at the beginning: right, first go and talk with industry, and we have also told industry: please come up with ideas of what you want to carry out within PoaC. In this way, projects were written with a better fit between what industry wants, on the one hand, and what the scientific world has to offer, on the other hand. We aligned this better' (member programme committee).

The second intervention is to use industrial relevance or applicability as an official criterion for selecting projects. Its precise operationalization and weight varied across the programmes and over time, but in all cases it has served as one of the decisive criteria. Together, these two interventions provide industry with the opportunity to influence the content of the programmes and projects.

This coordination process is directed at enhancing the benefits that the programmes create for industry. Besides a couple of product or process innovations, chemical firms have benefited significantly from the possibilities to train and recruit new R\&D staff and to strengthen their networks with other firms, which has led to several new industrial collaborations and business opportunities. In addition, the B-Basic programme has enhanced the societal awareness of a possible, bio-based economy by implementing a substantial education project.

\section{Interactions Within Programmes}

The ACTS programmes have functioned as effective platforms to facilitate interaction among researchers working on a similar topic. Regarding this type of coordination, a distinction should be made between regular interactions and collaborations.

Many ACTS researchers feel associated with the community of researchers active in their programme, thanks to regular meetings with the whole programme or with a subset of members working on a particular theme. On these occasions, researchers give feedback to each other on the progress of their projects. As the following quotes illustrate, the effects of such contact on the research direction varies across projects:

'And a number of times we have had meetings with all groups working within B-Basic, or at least with those who had this in their portfolio, and everyone worked a bit towards the same goal. We had a purely chemical approach, there were also people of... I think it was DSM... who were trying to fix it in a more enzymatic way, and... there was this other group collaborating with us that wanted to use elements from us in their research question. But what I have to say is that it was still mainly: we did our thing and they did their thing, so to say' (PhD student). 
"An enthusiasm like "we have to accomplish something together". This has also made people really talking to each other and trying: "given what I am doing in a certain area on a certain compound, it is practical if somebody else calculates something on the same compound". And not a completely different one, what he would normally do, then he would pick something that he fancies' (full professor).

Programme and theme meetings have created several relationships among the activities of some of the researchers. Researchers report cases of task division (complementarity), thematic convergence (similarity), timing of activities (synchronicity) and adjustments that make work more useful for fellow programme members (relevance). These relationships seem strengthened by a shared notion of the technological promise of their programme, which is often articulated in the form of a prospective chain consisting of a number of challenges to be tackled (Bakker et al. 2011). Apart from the contributions that these interactions have made to the performance of the projects, they have also contributed to the human capital developed. PhD students have learned about topics they would otherwise not have come across, and they have built up a network that may be beneficial in a later career stage.

Besides relations among researchers, the programmes also facilitate relationships between researchers and industrial stakeholders. The strongest intervention to this end is definitely the establishment of user committees. These groups of industrial representatives give feedback on the progress of individual projects, themes or the programme as a whole (aggregation level varies across programmes). Contact with users increases the awareness of academic researchers of potential practical applications for their work. This regularly leads to minor adjustments within projects in order to enhance their relevance for industry, but in a few exceptional cases a major influence on the research problem or approach has been reported, when a PhD student chose to collaborate actively with a particular firm. In such a case, complementary activities of academic and industrial researchers together lead to industrial innovation.

A significant number of researchers actively collaborated within an ACTS programme, in the sense of sharing resources for the sake of a common goal, such as a publication. This sometimes concerned official collaborative projects purposefully designed as a common activity for two or more organizations. In other cases researchers spontaneously decided to collaborate on a particular part of their work. Collaborations often enhance the efficiency of a programme, because it enables exploiting 'spillovers', which implies that a relatively small additional effort can yield an extra publication.

\section{Protecting Intellectual Property Within Programmes}

A relatively simple mechanism is in place to improve the protection of intellectual property. In all programmes there is a rule that researchers should show the manuscripts of their papers to industrial users before publishing. This intervention increases the acquaintance of industry with the research results and gives them the 
opportunity to request a patent application. ${ }^{4}$ Although in most cases no further action is taken, this rule increases the chances of successfully applying for patents and of eventually creating economic benefits from the knowledge produced in ACTS programmes.

\section{Competitive Project Selection}

Most programmes select their projects based on a competitive call for proposals and external peer review according to standard NWO procedures. This means that the programme committee uses the referee reports to make a ranking of projects, and advises the EB which projects to fund. ${ }^{5}$ When ranking projects, committee members have to leave the room when their own proposals are discussed. This selection approach creates a competitive relationship among researchers interested in funding from ACTS programmes. It challenges them to write proposals of sufficient quality to beat the competition. The entrance to this competition is restricted to a limited number of scholars working on topics that fit the call for proposals. Moreover, given the decisive power of the programme committee, personal interests and preferences can play a role. Given these two aspects, the market metaphor sometimes used to describe competitive funding (Lepori 2011) seems inappropriate here. The mechanism at work is like a beauty contest in which a jury evaluates the participating proposals based on a formal set of criteria, combined with subjective assessments. Challenged by this contest, the scientific field produces a number of proposals that are of sufficient quality to satisfy the programme committee's needs.

\section{Synthesis}

Comparing the various processes identified, a couple of general observations can be made about the relationships, mechanisms and types of performance. The interventions by ACTS are oriented at different types of performance. If we postulate innovation in the chemical sector as the overall aim of all coordination efforts by ACTS, most coordination processes address a particular sub-goal that serves this aim, such as public funding, human capital and scientific productivity.

Almost all relationships that ACTS mobilizes by its coordination processes imply proximity among the activities, in the sense that various activities are brought closer together. Within this family of relationships, a gradual scale is visible, ranging from weak ties (acquaintance) to stronger ties (similarity) and even interdependence (collaboration). The exception to this rule is competition, which implies that different activities are placed in mutual opposition rather than in a coalition.

\footnotetext{
${ }^{4}$ It should be noted that there is a lot of dissatisfaction on the sides of both academic researchers and industrial users about the details of the IP agreements. However, this mainly concerns the rules about who precisely is allowed to patent and how the potential revenues will be shared. The obligation to provide access to knowledge before publication is relatively widely accepted as an adequate procedure.

5 B-Basic is a notable exception, as it has been funded by Bsik based on a competition with other (aggregated) programme proposals already specifying a fixed set of projects and project leaders.
} 
The mechanisms at work seem quite varied and are difficult to summarize under a common heading. Nevertheless, three mechanisms reoccurred in various processes, which indicates that these might be rather general patterns: economies of scale, learning and team work. The first regards the efficiency gained when activities are undertaken collectively. Negotiating about research contracts collectively consume less time than individually. And sharing knowledge and research facilities may increase the total yield. The learning mechanism is similar but also involves the principle that experiences are shared, including errors and mistakes. The mechanism of team work concerns a task division that leads to synergies: actors carry out complementary activities, with mutual benefits.

\section{Conclusions and Discussion}

Science systems are in transformation, but a sound, empirically-supported understanding of the changes and continuities is lacking (Hessels and van Lente 2008). This paper deals with an increasingly prominent feature in the governance of science: intermediary organizations with a coordinating mission. I use the current rise of this type of organization as an opportunity to rethink the idea of coordination and to empirically investigate manifestations of coordination in science. In this endeavour I build on Lepori's approach to coordination in science (Lepori 2011). Extending his concept of coordination enabled me to address a broader set of governance processes than research funding only.

Starting from the definition of coordination as the establishment or strengthening of a relationship among the activities in a system, with the aim to enhance their common effectiveness, I have developed a heuristic framework to systematically characterize various types of coordination in the science system. The first benefit of my framework is that it makes it possible to distinguish between spontaneous and intentional coordination and to discern different levels of aggregation at which coordination takes place. Second, it facilitates a systematic characterization of coordination processes in terms of a limited number of key aspects.

A case study of the Dutch task force 'Advanced Chemical Technologies for Sustainability' (ACTS) illustrates the strengths of my framework. The framework made it possible to distinguish and characterize a number of coordination processes. The insights gained by this exercise help to understand the functioning of a coordination body such as ACTS. Thanks to the framework I could disentangle a number of functions that ACTS fulfils concerning research programming, funding allocation and supporting interactions and collaborations. This approach enabled me to systematically analyse a very heterogeneous set of processes that each deserve to be called coordination. The analysis yields a clear overview of eight coordination processes, which are each described in terms of activities, intervention, relationships, mechanisms and performance.

I have made a first step towards synthesizing the findings and identifying common patterns among the coordination processes observed. A variety of interventions was observed, ranging from setting rules for the allocation of funding to the physical colocation of staff of different organizations. The observed coordination processes vary 
strongly regarding the types of performance aspired and the mechanisms involved. In terms of relationships, however, some patterns are visible. Several processes utilize similarity among activities, and in these cases, economies of scale is often the responsible mechanism. In other cases, relevance or complementarity leads to higher performance, thanks to the mechanism of teamwork, in the sense of effective task division.

A number of striking outcomes of the case study deserve to be mentioned here. First, the two strongest coordination processes concern the shaping of research programmes in their design phase. The strongest benefits of ACTS seem to be the enlarged negotiation power of a combined set of coherent research plans, and the collaboration and task division with the division of chemical research $(\mathrm{CW})$ at NWO. Most of the coordination processes observed relate to the allocation of funding. Only two of the eight coordination processes observed in total take place after the money has been distributed to individual projects.

Second, ACTS hardly involves any hierarchical coordination with regard to the research content. Both the direction of ACTS and the programme committees value the autonomy of individual researchers to shape their own projects on the lab floor. There are rules and regulations concerning the way that funding is allocated, but we found hardly any evidence for hierarchical steering of the content of research. ACTS provides soft incentives that stimulate mutual interaction among the researchers in the programmes and protect the coherence of the research programme, but no compelling structures are in place. Participants are invited rather than forced to meet each other regularly, and there are little to no penalties for researchers deviating from their original proposals. This leaves room for researchers to benefit opportunistically from ACTS funding by adapting their research proposals strategically to a programme's needs, without making a real effort to contribute to the programme's goals (Morris 2000).

Third, ACTS hardly stimulates interaction among the programmes. One could expect a task force like ACTS to enhance the common focus of the various programmes or to stimulate collaborations among them for the sake of productivity, interdisciplinary learning and innovation. In practice, however, the five programmes of ACTS function to a large extent independently in terms of research. Bundling them in one common organization creates synergies in terms of bureaucratic efficiency, but not in terms of knowledge spillovers or research collaborations.

Empirical analyses of coordination in science are required for the governance of science and innovation. In today's policy discourse, coordination seems a popular notion, with mainly positive connotations. This article has dealt primarily with the (potential) benefits of coordination, but we must also be aware that coordination comes with a price. Intermediary organizations like ACTS often have relatively low overhead costs, as their management staff is hired only part-time. Still, there are a number of hidden costs, in particular related to the time required to write research proposals, negotiate about terms and conditions, assess and select research proposals (both by programme committees and by external peers), and provide standardized information that facilitates systematic monitoring and evaluations. Besides these costs, a science system with too many coordinating bodies runs the risk that their efforts interfere (van den Besselaar and Horlings 2010). This creates confusion for 
researchers, because they no longer understand which organization is responsible for what, but it can also lead to the inhibition of effects if two organizations are counteracting each other. Although such costs and risks cannot be addressed in the current paper, they should be taken into account for making a full assessment of the desirability of coordinating organizations.

To close, I will offer a few suggestions for further research on coordination in science. First, after the qualitative case study presented here, quantitative measurement of coordination using bibliometric analysis seems a fruitful avenue. Mapping the trends in the research output of task forces like ACTS provides insight in the degree to which the expected thematic similarity indeed develops among the funded activities. The observations should be compared with a control dataset covering the global output of the field or the output in a country where no coordinating task force is active in the area. Co-authorship analysis can indicate collaborative relationships. A detailed analysis of the portfolio of individual researchers can reveal the influence of particular coordination interventions on their research agenda.

Second, a comparison between coordination approaches in different scientific fields is desired. As 'authority relations' vary across scientific fields (Gläser et al. 2010), we can expect to find different coordination processes across scientific fields. Whitley's typology in terms of mutual dependence and task uncertainty (Whitley 2000) will be helpful here. Fields with a high technical dependence involve more spontaneous coordination. For example, particle physicists have to plan their activities collectively in order to make any progress (Knorr-Cetina 1999). In fields with a high strategic task uncertainty, it will be more difficult to aggregate research proposals and negotiate collectively for funding. Another interesting comparison is between coordination in converging and diverging search regimes (Bonaccorsi 2008).

A third interesting empirical direction is to analyse coordination on the supranational level, such as in the European Framework Programmes. The European Networks of Excellence employ a variety of approaches to coordination (Bonaccorsi 2010; Luukkonen et al. 2006), and they could form a valuable entry point to explore the differences between national and international coordination processes. I expect that the larger geographical distance, cultural barriers and varying institutional contexts make coordination more difficult on a European scale. Another interesting topic is the relationship between coordinating efforts at the national versus the supra-national level. The choice of priority themes on the European level may be purposefully copied in one country but deliberately ignored or even actively rejected in another. Given the continuing shift towards European research funding, the effects of interfering coordination on national and supra-national levels will be a complex but increasingly topical research issue.

Acknowledgments The author wishes to thank the ACTS office and all interviewees for their cooperation; Pepijn Wesselman for assistance in data collection; and all colleagues from the department of Science System Assessment of the Rathenau Instituut for helpful comments and discussions. Moreover, Colja Laane, Jochen Gläser, Grit Laudel, Bernd Kleimann, Harro van Lente and the participants of the workshop 'Understanding Research Coordination', 14-16 March 2012 in Amsterdam, are gratefully acknowledged for constructive feedback on an earlier draft. 


\section{References}

Bakker, Sjoerd, Harro van Lente, and Marius Meeus. 2011. Arenas of expectations for hydrogen technologies. Technological Forecasting and Social Change 78(1): 152-162.

Bonaccorsi, Andrea. 2008. Search regimes and the industrial dynamics of science. Minerva 46(3): 285-315.

Bonaccorsi, Andrea. 2010. New forms of complementarity in science. Minerva 48(4): 355-387.

Bonaccorsi, Andrea, and Andrea Piccaluga. 1994. A theoretical framework for the evaluation of university-industry relationships. R\&D Management 24(3): 229-247.

Bozeman, Barry, and Elizabeth Corley. 2004. Scientists' collaboration strategies: Implications for scientific and technical human capital. Research Policy 33: 599-616.

Braun, Dietmar. 2003. Lasting tensions in research policy-making-a delegation problem. Science and Public Policy 30(5): 309-321.

Braun, Dietmar. 2008. Organising the political coordination of knowledge and innovation policies. Science and Public Policy 35(4): 227-239.

Clark, Burton R. 1979. The many pathways of academic coordination. Higher Education 8: 251-267.

Clark, Jennifer. 2010. Coordinating a conscious geography: The role of research centres in multi-scalar innovation policy and economic development in the US and Canada. Journal of Technology Transfer 35: 460-474.

Cummings, Jonathon N., and Sara Kiesler. 2007. Coordination costs and project outcomes in multiuniversity collaborations. Research Policy 36: 1620-1634.

Dasgupta, Partha, and Paul A. David. 1994. Toward a new economics of science. Research Policy 23(5): 487-521.

Edler, Jacob, and Stefan Kuhlmann. 2008. Coordination within fragmentation: Governance in knowledge policy in the German federal system. Research Policy 35(4): 265-276.

Fisher, Donald, Janet Atkinson-Grosjean, and Dawn House. 2001. Changes in academy/industry/state relations in Canada: The creation and development of the Networks of Excellence. Minerva 39(3): 299-325.

Gläser, Jochen, Stefan Lange, Grit Laudel, and Uwe Schimank. 2010. The limits of universality: How field-specific epistemic conditions affect authority relations and their consequences. In Reconfiguring Knowledge Production: Changing Authority Relationships in the Sciences and their Consequences for Intellectual Innovation, eds. R. Whitley, J. Gläser, and L. Engwall, 291-325. Oxford: Oxford University Press.

Gray, Denis O. 2011. Cross-sector research collaboration in the USA: A national innovation systems perspective. Science and Public Policy 38(2): 123-133.

Hessels, Laurens K., and Harro van Lente. 2008. Re-thinking new knowledge production: A literature review and a research agenda. Research Policy 37: 740-760.

Hessels, Laurens K., and Harro van Lente. 2011. Practical applications as a source of credibility: A comparison of three fields of Dutch academic chemistry. Minerva 49(2): 215-240.

Kearnes, Matthew, and Matthias Wienroth. 2011. Tools of the trade: UK research intermediaries and the politics of impacts. Minerva 49(2): 153-174.

Klerkx, Laurens, and Cees Leeuwis. 2008. Delegation of authority in research funding to networks: Experience with a multiple goal boundary organization. Science and Public Policy 35: 183-196.

Knorr-Cetina, Karin D. 1999. Epistemic Cultures. Cambridge: Harvard University Press.

Lepori, Benedetto. 2011. Coordination modes in public funding systems. Research Policy 40(3): 355-367. doi:10.1016/j.respol.2010.10.016.

Luukkonen, Terttu, Maria Nedeva, and Remi Barré. 2006. Understanding the dynamics of networks of excellence. Science and Public Policy 33(4): 239-252.

Morris, Norma. 2000. Science policy in action: Policy and the researcher. Minerva 38: 425-451.

Polanyi, Michael. 1962. The republic of science: Its political and economic theory. Minerva 1: 54-74.

Poti, Bianca, and Emanuele Reale. 2007. Changing allocation models for public research funding: An empirical exploration based on project funding data. Science and Public Policy 34(6): 417-430.

Powell, Walter W. 1990. Neither market nor hierarchy: Network forms of organization. Research in Organizational Behavior 12: 295-336.

Sundberg, Mikaela. 2011. The dynamics of coordinated comparisons. Social Studies of Science 41(1): 107-125. 
Technology Roadmap Catalysis: Catalysis, Key to Sustainability. 2002. Den Haag: Ministerie van Economische Zaken.

Thompson, G., J. Frances, R. Levacic, and J. Mitchell. 1991. Markets, Hierarchies and Networks: The Coordination of Social Life. London: SAGE.

van den Besselaar, Peter, and Edwin Horlings. 2010. Focus en massa in het wetenschappelijk onderzoek: De Nederlandse onderzoeksportfolio in internationaal perspectief. Den Haag: Rathenau Instituut, SciSA rapport 1016.

van der Meulen Jr, Barend, and Arie Rip. 1998. Mediation in the Dutch science system. Research Policy 27(8): 757-769.

van Lente, Harro, and Arie Rip. 1998. The rise of membrane technology: From rhetorics to social reality. Social Studies of Science 28(2): 221-254.

van Vught, Frans A. 1997. Combining planning and the market: An analysis of the Government strategy towards higher education in the Netherlands. Higher Education Policy 10(3/4): 211-224.

Versleijen, Anouschka. 2007. Dertig jaar publieke onderzoeksfinanciering in Nederland 1975-2005: Historische trends, actuele discussies. Den Haag: Rathenau Instituut, SciSA rapport 0703.

Whitley, Richard. 2000. The Intellectual and Social Organization of the Sciences, 2nd ed. Oxford: Oxford University Press.

Whitley, Richard. 2003. Competition and pluralism in the public sciences: The impact of institutional frameworks on the organisation of academic science. Research Policy 32: 1015-1029.

Ziman, J. 1994. Prometheus Bound: Science in a Dynamic Steady State Cambridge: Cambridge University Press. 